\title{
Propuesta de un modelo antropológico-existencial del sentido de vida
}

An Antropological-existential Model of the Meaning of Life: A Proposal

María Victoria Cadavid Claussen ${ }^{\star}$

Víctor Manuel Díaz Soto*

Universidad Católica de Colombia

Recibido: 29 de junio del 2014

Enviado a pares: 29 de junio de 2014

Aceptado por pares: 8 de octubre de 2014

Aprobado: og de octubre de 2014

Pensamiento y Cultura | ISSN: 0123-0999 | eISSN: 2027-5331

pensam.cult | Vol. 17-2 | Diciembre de 2014 | pp. 145-180

DOI: 10.5294/pecu.2014.17.2.7

$\diamond$ mvcadavid@ucatolica.edu.co

*vmdiaz@ucatolica.edu.co 


\section{Propuesta de un modelo antropológico-existencial del sentido de vida}

Resumen: Este artículo pretende ofrecer una aproximación teórica para un mejor conocimiento de la temática del sentido de vida, así como proponer un método desde un modelo antropológico-existencial para la configuración de diversos tipos de sentido.

Este modelo recoge aportes de la filosofía clásica y contemporánea, así como de la antropología trascendental de L. Polo', y de la propuesta de sentido de la escuela logoterapéutica de V. Frankl².

El modelo de sentido de vida es una propuesta y aporte original de los autores, que surge de la correlación de las dimensiones antropológica y existencial, constitutivas del modelo a modo de ejes que configuran el plano del sentido de vida desde donde emergen los tipos de sentido formulados. Estas dimensiones son los radicales antropológicos del sentido (RAS) y las líneas de orientación al sentido (LOS).

Cabe aclarar que el modelo que aquí se presenta es susceptible de posteriores avances tanto a nivel teórico como metodológico y no pretende dar respuesta a la totalidad de la cuestión de las manifestaciones del sentido de vida humano.

Palabras clave: sentido de vida, tipos de sentido, radicales antropológicos, líneas de orientación al sentido.

\section{An Antropological-existential Model of the Meaning of Life: A Proposal}

Abstract: This article offers a theoretical approach to a better understanding of the issue of the meaning of life, and proposes a methododology to configure various types of meaning, from an existential anthropological model.

This model includes contributions of classical and contemporary philosophy and transcendental anthropology by L. Polo, and the proposal of meaning by V. Frankl Logotherapeutic School.

The meaning of life model is a proposal and original contribution by the authors, which emerges from the correlation of anthropological and existential dimensions, constituted as axes that form the plane of the meaning of life from which emerge the types of meaning. These dimensions are the Anthropological

1 Leonardo Polo. Filósofo español contemporáneo. Dentro de su obra propone la Antropología Trascendental.

2 Viktor Frankl. Psicoterapeuta austriaco del siglo XX, fundador de la Escuela de Logoterapia y Análisis Existencial. 
Roots of Meaning and the Orientation Guidelines to the Meaning of Life.

It is clear that the model presented here is capable of further advances both on a theoretical and methodological level and is not intended to answer the whole question of the manifestations of the meaning of human life.

Keywords: Meaning of life, types of meaning, anthropological roots, orientation guidelines to the meaning.

\section{1. ¿Por qué un modelo de sentido antropológico- existencial?}

El modelo de sentido que se presenta es en primer lugar respetuoso de la singularidad personal y no pretende resolver con plenitud de clarividencia lo que en buena medida corresponde más propiamente a la profundidad del ser personal que cada quien es y a sus singulares manifestaciones.

En segunda instancia, dicho modelo es una propuesta original de los autores con el ánimo de contribuir desde una mejor comprensión del sentido al desarrollo humano personal y social con posibilidades de aplicación educativa, corporativa y comunitaria.

Este modelo intenta aclarar los aspectos antropológicos del sentido, y su vinculación con la persona y su existencia. Por esta razón se proponen por una parte los radicales antropológicos del sentido, propios del ser personal, que debido a su indeterminación irrestricta se configuran en apertura a la búsqueda y descubrimiento de la verdad personal y de su destino (Polo 1999; Scheler 1998). Esta verdad es constitutiva del núcleo íntimo personal (Yepes 1997) que sale al encuentro del sentido en cada instante de su existencia como respuesta a su llamado.

Por otra parte, el sentido se puede descubrir como manifestación de significado valioso, dentro de las coordenadas biográficas de cada quien, porque su hallazgo puede ocurrir en cada circunstancia particular en la cual la persona humana se encuentre situada en un determinado momento y lugar (Frankl 2000, 33). 
Es por esta razón que además de los radicales antropológicos, se establecen unas líneas de orientación al sentido, como vías o cauces existenciales que posibilitan el encuentro con el sentido y que por su valor de manifestación personal son ámbitos significativos de optimización para las personas (Polo 1999; López Quintás 1994).

\section{Aproximación conceptual al modelo de sentido de vida}

Los factores que posibilitan y configuran el encuentro con el sentido de vida provienen de la persona, de su núcleo espiritual que, en este trabajo, se presentan como radicales antropológicos (Polo 1999) y de su existencia o biografía personal, los entornos familiar, educativo, social y cultural presentados como líneas de orientación al sentido (Aranguren Gonzálo 2000, 170-171). En esta combinación de aspectos se configura una dualidad de claves personales que por una parte constituyen a la persona en su intimidad y, por otra, forman parte de sus manifestaciones externas o esenciales porque facilitan o entorpecen la disposición al sentido, según sea la transparencia o apertura íntima de la persona. $\mathrm{Si}$ desde la intimidad personal el hallazgo de sentido es posible, y con ello la esperanza, en el caso de opacarse o estrecharse la apertura personal, el sentido se imposibilita, y sobreviene el sinsentido y con ello la desesperación. Se trata, por lo tanto, de evidenciar los factores dinamizadores o inhibidores del sentido de vida (Lukas 1994, 267).

Es así como se hace necesario definir cada uno de los factores que intervienen en el sentido de vida, los radicales antropológicos del sentido y las líneas de orientación al sentido de vida y sus diversos niveles.

Se definen los radicales antropológicos del sentido de vida como aquellos componentes que caracterizan a la persona humana como apertura y la posibilitan o predisponen para el encuentro de su sentido personal y el de su existencia. Por tanto, de estos radicales unos son constitutivos del núcleo personal, razón por la cual son iluminaciones únicas y singulares de cada quien, y otros se hacen presentes en las dimensiones de la esencia y de la naturaleza humana. 
Se entiende la esencia como la dimensión psíquica que comprende la inteligencia y la voluntad activadas por la persona (Polo 1999). La dimensión natural se refiere a la realidad puramente sensible y biológica común a la especia humana. Dicho de otra manera, los radicales antropológicos del sentido de vida son las notas de la persona humana que la capacitan bio-psico-espitualmente para la búsqueda y el descubrimiento del sentido de vida.

Los radicales antropológicos del sentido así entendidos son el humus del sentido, su origen manifiesto en la persona, presente en la verdad personal que cada quien es. Se constituyen entonces, estos radicales del sentido de vida, en fuente de la luz, del logos, que se proyecta en la esencia humana y por ende en la existencia del hombre en su despliegue vital.

Según este modelo, los radicales antropológicos del sentido contemplan también la esencia humana; no porque ésta sea su fuente, sino porque es preciso que dentro de un modelo antropológico existencial se encuentren contenidas todas las características que presentan al ser humano como ser de sentido, tanto como acto de ser - el sentido de ser quien es-, así como en su esencia - de lo que dispone para seguir siendo $y$ haciendo una existencia con sentido- (Polo 1999) en tanto posibilidad de desarrollo en plenitud de la persona humana multidimensional (Seligman 2003, 343).

Se ha dicho que la persona es apertura que tiene una orientación natural al sentido. Ahora bien, esta disposición antropológica del hombre de encararse frente a sí mismo y frente al cosmos lo lleva a configurar deliberadamente su orientación existencial. Hay que añadir que toda vida humana está abierta al vector de la felicidad - tesis fácilmente reconocible- y requiere además un sentido. Sentido y felicidad parecerían intercambiables; sin embargo, en sentido estricto y con una observación más atenta, no lo son. Los clásicos han definido la felicidad como aquel regalo de la vida buena, de la conquista de la virtud, del logro de la perfección posible (Aristóteles 2007, 283-290; Aquino 2001). En cambio el sentido se desvela o es descubierto por cada uno existencialmente en sus propios senderos, como un peregrino que encuentra en él - en el sentido- su rumbo y su posada, el alimento que nutre su existencia, el descanso de su 
búsqueda y el cielo que ilumina un nuevo amanecer. En fin, el sentido es al tiempo causa eficiente de la vida humana y causa formal de sus contenidos y vivencias; y aunque parezca medio para la felicidad porque lleva a ella (Martínez 2011, 237) e incluso sea su requisito (Marías 1987, 334) - una felicidad sin sentido resulta bastante triste-, puede afirmarse que ontológica y existencialmente es preponderante el valor del sentido sobre el de la felicidad. Aún sin felicidad el sentido es una luz en el horizonte que atraviesa la totalidad del ser humano: "podemos describirlo como la percepción de la trayectoria satisfactoria o insatisfactoria de nuestra vida" (Yepes y Aranguren 1996, 164).

Para definir los senderos existenciales que llevan a tal sentido de vida cabe cuestionarse: ¿qué aspectos de la existencialidad o situaciones vitales de la persona son oportunidad de conducirse hacia el descubrimiento de sentido? Estos contextos o situaciones vitales son lo que se denominan como líneas de orientación al sentido de vida y constituyen los cauces o escenarios existenciales que son modo de "conducirse hacia" o "situarse para" el descubrimiento de sentido porque implican el despliegue en la existencia de la persona de sus radicales antropológicos de sentido. Las líneas de orientación al sentido son entonces factores de sentido que se entienden como ámbitos de interacción entre la persona y lo que le ocurre en la vida y entre la persona y lo que esta realiza intencionalmente con su vida.

De esta manera, a cada línea de orientación al sentido le corresponde el máximo del esfuerzo por la captación de valores como extensión de la apertura personal íntima y originaria. No es esta dinámica exactamente como el volverse virtuoso. Las virtudes son habilidades adquiridas por cada hombre para optimizar sus capacidades en orden a la armonía personal para realizar el ideal de una vida bella y llena de sentido (Aranguren 2003, 169). El sentido es el modo más profundo de responder al interrogante de quién soy, porque es la luz que define la identidad personal, al mismo tiempo que en ese sentido su existencialidad se le hace transparente a la persona. En definitiva, las líneas de orientación al sentido de vida encauzan a la persona al encuentro con la presencia clara y profunda de contenidos llenos de significación y de valor. Además estas líneas de orientación facilitan al hombre mantener 
la actitud de disposición, de apertura permanente a la captura consciente de valores, capaces de ofrecerle sentido de vida.

El situarse de la persona en su existencia la lleva a encontrarse en estado permanente de decisión, que es el momento clave de la libertad (Burgos 2003a, 177) porque contempla la vertiente de la elección, como decisión intencional-horizontal en relación con lo exterior que conlleva siempre una vertiente interior de decisión sobre sí mismo, de autodeterminación personal. En la existencia estas dos vertientes se dan simultáneamente constituyendo la libertad real. La persona, como se ha dicho, despliega sus radicales antropológicos de sentido en ámbitos existenciales en los que se orienta bien al sentido, con la disposición sostenida para el encuentro con los valores objetivos, o bien al contrasentido, desde un consentir la convivencia con antivalores.

Los valores son objetivos, porque no nacen del interior del hombre sino suponen algo que procede de un nivel superior a él, y es por ello que tienen la capacidad de presentarse como "desafío" o reto para el hombre, para emplazarlo e interpelarlo con un "carácter imperativo" de deber exigente e inapelable.

Responder de una manera convincente a la pregunta por el sentido de la vida exige dos cosas: tener una tarea que nos ilusione y enfrentarse con las verdades grandes, con los grandes interrogantes de nuestra existencia. Quien sabe responderlos sabe lo que verdaderamente le importa, lo que merece la pena tomarse en serio. Dicho de otro modo: saber cuáles son los valores verdaderamente importantes para mí es lo que hace posible emprender la tarea de realizarlos. Crudamente expresado: se es hombre cuando se tiene saber teórico y capacidad práctica para responder a estas tres preguntas: ¿Por qué estoy aquí? ¿Por qué existo? ¿Qué debo hacer? De otro modo se pierde el tiempo (Yepes y Aranguren 1996, 165; Juan Pablo II 1995, 159).

El hombre puede responder o no ante un valor objetivo pero siempre sabe de su presencia. La oposición ante el valor objetivo puede llevarlo al contrasentido, es decir, a la opción contraria al valor, el antivalor. En cambio el hombre que inventa su propio sentido o valor subjetivo, sin tener este 
refrendo en la realidad, intencionalidad del valor, se encierra o se repliega a un mundo fantasioso que no corresponde ni con la realidad ni con su verdad interior. El hombre se halla expuesto a ámbitos vitales cuyo vector de orientación vital lo llevan al sentido y en este caso se denominan líneas de orientación al sentido o se encuentra frente a vectores de orientación vital que lo alejan del sentido y lo llevan activamente a un contrasentido, y en este caso se consideran líneas de orientación al contra-sentido.

\section{Los radicales del sentido y sus niveles}

Los radicales antropológicos de sentido se presentan en tres niveles: sensible, psíquico y espiritual. Los radicales espirituales se reconocen como originarios del núcleo personal, se despliegan en plenitud de trascendencia y pertenecen a la dimensión espiritual. Estos otorgan a la persona la luz propia de su intimidad que se proyecta en todas las demás dimensiones humanas. Estos radicales espirituales son los que ubican el sentido de vida en una actitud objetiva personal y existencial. Lo cual significa el posicionamiento vital personal como actitud valorativa fundamental frente a la realidad de su propio valor manifiesto en el principio de alteridad ante el otro y, en general, ante todo el cosmos; en razón de estos radicales espirituales se conjugan desde la persona el conocimiento de su sentido personal y el de la multiplicidad de sentidos que es capaz de descubrir en el mundo. Por estos radicales espirituales la persona, que es apertura, sale al encuentro de los valores personales y existenciales.

Por otra parte, se encuentran los radicales que pertenecen al nivel psíquico de manifestación de la persona y disposición al sentido, más estrechamente ligado a la respuesta existencial. Desde estos radicales la persona adquiere experiencia, se propone proyectos y aprende, genera alternativas, elige su modo de existir y promueve distintas empresas; también conforma ámbitos de relaciones, es decir, desarrolla el trabajo de la propia realización y su aporte a la existencia humana. Así, los radicales psíquicos son como un puente entre la intimidad, núcleo espiritual de la persona, y su naturaleza sensible; y al mismo tiempo son también cauces de comunicación entre la interioridad personal y sus infinitas posibili- 
dades de manifestación externa en la palabra, las actitudes y las obras. Es la posibilidad siempre presente para el hombre de disponer de su naturaleza como "perfeccionador perfectible" (Polo 2007, 562; Sellés 1998, 111).

En un tercer nivel, los Radicales en su manifestación sensible son de la naturaleza humana que también expresa la apertura personal. Gracias a los sentidos externos e internos el mundo es asumido y retenido, imaginado y futurizado en la corporeidad situada en lo necesario, pero que manifiesta el sobrarse de la espiritualidad que la ilumina, una biología diseñada para ser biografía. Los radicales sensibles son la frontera de la persona con el mundo y por esto se incluyen para este modelo dentro de los radicales antropológicos del sentido. Sin ellos, la persona no puede saberse situada en el mundo porque el contacto inmediato es posible a través de ellos.

Los niveles de los radicales antropológicos descritos, corresponden con los niveles que Frankl presenta como voluntades de sentido, de poder y de placer (Frankl 2001, 22). Análogamente, ya Aristóteles reconocía tres niveles del dinamismo de la apetitividad y las tendencias humanas (Malo 2004, 95-104): la epythimia, el thymos y la boulesis, correspondientemente, apetitos concupiscible, irascible y racional (la voluntad), como los ha denominado el pensamiento clásico. A la antropología le corresponde el estudio de la persona humana, no sólo como acto de ser, en la perspectiva ontológica, sino también como fuente de sentido, como logos. De ello se infiere que la persona es superior a su esencia y que se auto-posee. Como se autoposee en libertad, le es posible autodeterminarse (Franquet 1996).

Es imperativo declarar que el fundamento de los radicales de sentido es la libertad, asumida como una noción trascendental (Polo 2005, 9), que no sólo está presente en el acto de ser personal, sino que se comunica a las otras dimensiones del ser humano que no son trascendentales: la esencia y la naturaleza. Como consecuencia de la libertad aparece, en el mismo nivel, la responsabilidad. Por ser libre, la persona es capaz de llenar de contenido la propia existencia y verterlo en el espacio humano donde se sitúa la persona y sus circunstancias.

Luego que la orientación al sentido se vuelve hacia la confrontación con el sentido, se alcanza un estadio de madurez y desarrollo en el que la libertad - ese concepto tan subrayado por la filosofía existencialista- se 
vuelve responsabilidad. El hombre es responsable de la realización del sentido específico de su vida personal. Pero es responsable ante algo o para algo, sea lo sociedad, el género, la humanidad o su propia conciencia. Sin embargo, hay un importante número de personas que interpretan su propia existencia, no sólo en términos de ser responsables para algo, sino también para alguien, a saber, Dios (Frankl 2001, 28).

La libertad personal en el mismo situarse singularmente de la persona en su existencia despliega en primera instancia los radicales espirituales del sentido como modo de autodeterminarse en el sentido desde la dimensión más profunda de su ser, la espiritual, la que denomina Frankl voluntad de sentido y por la que se alcanza el modo humano de existir, como corresponde a la persona en tanto fin en sí misma. En segunda instancia de estos radicales espirituales del sentido se derivan los radicales psíquicos, cuyo despliegue corre a cargo de la voluntad de poder y se constituyen como medio, de autorrealización, para alcanzar el fin del cumplimiento del sentido. En tercera instancia se derivan los radicales sensibles del sentido cuyo despliegue está motivado por la voluntad de placer y son efecto de la realización de sentido y asegura la sobrevivencia. En conclusión mientras los radicales espirituales apuntan al fin, el sentido, los psíquicos son un medio, el poder, y los radicales sensibles son el efecto, el placer: "La voluntad de poder y la búsqueda de placer, es decir, el principio de placer, aparecen propiamente cuando se frustra la voluntad de sentido" (Frankl 1994a, 24).

La voluntad de sentido es más íntima al ser de la persona que su realización existencial efectiva, por eso siempre llama a más existencia. El principio de la voluntad de sentido está en la misma libertad originaria del núcleo espiritual de la persona, de la intimidad irreductible que es. Se considera apropiado en este punto consignar un fuerte cuestionamiento que hace Frankl sobre el propósito de las potencialidades humanas.

¿Debería el hombre únicamente desarrollar sus potencialidades internas o -como también suele decirse- expresarse a sí mismo? El motivo oculto que hay detrás de nociones de este tipo es, a mi entender, disminuir la tensión surgida por la distancia que hay entre 
lo que somos y lo que debemos ser, la tensión entre el estado actual de cosas y el estado ideal que hay que materializar; la tensión entre la existencia y la esencia, o como también podríamos decir entre el ser y el sentido (Frankl 2001, 25).

En adelante se abordarán de modo específico cada uno de los niveles enunciados y sus respectivos radicales. Los radicales espirituales corresponden a la voluntad de sentido, al descubrimiento del fin personal, del sentido personal y su despliegue en la existencia:

1. Autoconocimiento: capacidad para mirarse, comprenderse y conocerse desde la misma posibilidad que tiene el hombre de autodistanciarse, de situarse frente a sí mismo. Es el conocimiento de la conciencia en torno a sí misma, en tanto se posiciona con firmeza al tomar distancia del mundo y de nosotros mismos (Burgos 2003a, 202; Quitmann 1989).

2. Autodeterminación: presupone la autoposesión: se puede decidir únicamente sobre lo que se posee y solo puede decidir quien posee. El hombre se autodetermina porque se posee, tiene la capacidad de decidir sobre sí mismo y sobre el rumbo de su propia vida en amplitud de las posibilidades que se abren frente a la persona. Por eso es providente sobre sí misma al punto de llegar a ir contra su propia naturaleza.

El dinamismo de la autodeterminación consiste en la utilización de la voluntad por el hombre [...]. La voluntad está subordinada en relación con la persona y no determina ni gobierna a la persona. La expresión libre voluntad no significa cierta forma de independencia de la voluntad en relación con la persona. Si estamos de acuerdo en que la libertad de la voluntad se manifiesta al experimentar que podría, pero no es necesario, eso expresa a la persona que puede, pero no necesita utilizar su libertad en cuanto fuerza (Wojtyla 1982, 142).

3. Autotrascendencia: capacidad de dar de sí mismo y de salir de sí porque la persona y su existencia humana son apertura. Esto significa 
que el hombre no es un sistema cerrado empeñado en la autoactualización de su sí mismo sino en la realización de valores y en la realización de posibilidades de sentido que han de encontrarse en el mundo más que dentro de uno mismo (Frankl 2001, 79).

4. Creatividad: parte del dinamismo inmanente de la persona, que es siempre originaria, para recibir y dar al mundo. La persona es fuente de creatividad, tanto artística o estética como existencial o vital, porque ella misma es causa de novedad y, por ello, condición de posibilidad y de riqueza existencial (García Pintos 2004). La creatividad es en sí la realización de la belleza aunque también se manifiesta en sus consecuentes ejercicios: capacidad de solucionar problemas, aportar al conocimiento, dinamizar la cultura.

5. Afectividad espiritual: está compuesta por los sentimientos espirituales. Es la capacidad de afectarse espiritualmente con sentimientos profundos que tocan al núcleo personal, e indican el estado de la intimidad (Sellés 2010, 97 y 117), su lucidez o su opacamiento en sentimientos de culpa o de alabanza (Lacroix 1980), de paz y esperanza o de desesperación y desconcierto (Freire 2002), de alegría o tristeza, de amor o de odio, de misericordia o soberbia; siempre en ese rango y profundidad del corazón humano (Hildebrand 2001, 33).

6. Contemplación: apertura para la belleza, aquello que agrada al conocimiento, y también experiencia de admiración ante la verdad (Aristóteles 2007). Al tiempo, es superación de la temporalidad espacial en que se inscribe la existencia humana. Es por eso, conciencia de gratuidad, de don y encuentro con la armonía del mundo, la vida y del ser. Es también apertura lúdica pues es capacidad para recrearse, contemplar y descansar creativamente.

7. Esperanza: es la actitud dinámica de espera confiada en la plenitud del ser personal. Anhelo de eternidad. Se basa en el conocimiento de verdad y anticipación de perfección como fuente viva de ese anhelo. Es tensión entre lo que se es y lo que se puede llegar a ser que se derrama luego en toda la acción vital (Aranguren Gonzálo 2000). 
Los radicales psíquicos son del nivel de la voluntad de poder y constituyen los medios para la manifestación personal en el habitar y dominar del mundo:

8. Hacer-productividad: es el responder ante la vida misma la respuesta que se debe responder; la acción que concreta la respuesta ante una situación concreta y que se enmarca dentro del existir de cada día, la necesidad de la obra; del realizar su vida de una manera singular, que depende de cómo la haga, de qué es lo que hace. Es posibilidad de creación de valores desde su trabajo.

9. Tener: viene de habere y se relaciona con habitum. Es la posesión de un espacio en el que las cosas hacen referencia a la propia persona. Esa realidad cobra sentido en cuanto poseída por la intimidad de quien la tiene.

10. Pertenecer: capacidad de identificarse y saberse acogido por un grupo social. Es la necesidad de conocimiento de la identidad, de raíces, de origen, de conocimiento de la propia procedencia y del ser necesitado por otro. Al mismo tiempo es el poder dirigirse al encuentro de otro por quien se es bien recibido y establecer vínculos.

11. Saber: resultado del conocimiento como apertura del hombre a la realidad, que incluye el darse cuenta de que conoce y de que se conoce a sí mismo. Tiene que ver con la apertura y la atracción por la verdad, el interés por el ser de las cosas (Sellés 1997).

12. Afectividad emocional: son sentimientos psíquicos, intelectuales o volitivos, como capacidad de afectación psíquica con los estímulos del entorno por estas facultades. Son estados de ánimo propios de las potencias inorgánicas que informan sobre el estado de las mismas (Polo 1987, 272 y 276; Sellés 2010, 109).

Los radicales sensibles pertenecen al nivel de la voluntad de placer y son los correspondientes a las necesidades biofísicas de la persona humana:

13. Seguridad y protección físicas: necesidad de lugar, de refugio y abrigo. 14. Afectividad sensible: los sentimientos sensibles son estados de ánimo sensibles que acompañan el conocimiento sensible, al 
ejercer la capacidad de percibir la realidad a través de las sensaciones. Estos sentimientos son el agrado o desagrado del actuar bien o no de cada facultad, como refiere Sellés:

Los sentimientos sensibles surgen, pues, de comparar si éste o el otro acto cognoscitivo, o si éste o el otro acto apetitivo, es adecuado o no, va bien o mal, al estado, también corpóreo, cambiante y transitorio de la facultad sensible, sea cognoscitiva o apetitiva; comparación que tiene en cuenta no sólo la índole de tales actos sino también el estado actual de la facultad sensible (Sellés 2010, 136).

15. Descanso-vitalidad: después de la fatiga y el esfuerzo vital de los movimientos corporales que se realizan diariamente, se reponen las fuerzas del organismo con el cese o cambio de actividad.

16. Salud-nutrición: la salud es la posibilidad de contar con la base orgánica en estado funcional y armónico que sin la nutrición no es posible.

17. Contacto social: no solo venimos al mundo por otros sino que llegamos en sus manos, necesitamos la presencia de otro, aunque sea distante, como se evidencia también en los requisitos mínimos de supervivencia humana: nadie sobrevive humanamente sin un mínimo contacto con lo humano en el otro.

En definitiva se han descrito los niveles en los que se presentan los radicales antropológicos de sentido, en los que se evidencia una tensión que, según sea positiva o negativa con relación al sentido, determinan los modos de despliegue o inhibición en el que se presentan (Cuadro 1).

¿Puede enfermar el espíritu? Seguramente que no de las enfermedades que el lenguaje corriente llama enfermedades mentales. En éstas, se trata de perturbaciones de las funciones cerebrales, de la vida instintiva, del curso de las representaciones, de la experiencia de la realidad, etc. Tales perturbaciones no afectan al espíritu como tal, sino sólo a sus fundamentos orgánicos y psíquicos. Estas perturbaciones obstaculizan 
Cuadro 1. Radicales antropológicos de sentido y dinámica de tensión existencial

\begin{tabular}{|c|c|c|c|c|c|}
\hline $\begin{array}{l}\text { VOLUN- } \\
\text { TADES }\end{array}$ & $\begin{array}{c}\text { NIVELES } \\
\text { DE RADI- } \\
\text { CALES } \\
\text { DE } \\
\text { SENTIDO }\end{array}$ & RADICALES & $\begin{array}{c}\text { TENSIÓN } \\
\text { POSITIVA } \\
\text { DESPLIEGUE }\end{array}$ & $\begin{array}{c}\text { TENSIÓN } \\
\text { NEGA- } \\
\text { TIVA } \\
\text { INHIBI- } \\
\text { CIÓN }\end{array}$ & LOGRO \\
\hline \multirow[t]{7}{*}{$\begin{array}{l}\text { VOLUNTAD } \\
\text { DE } \\
\text { SENTIDO }\end{array}$} & \multirow[t]{7}{*}{$\begin{array}{l}\text { Espiri- } \\
\text { tuales }\end{array}$} & $\begin{array}{l}\text { Auto-distancia- } \\
\text { miento } \\
\text { (conocimiento- } \\
\text { inteligencia) }\end{array}$ & \multirow[t]{7}{*}{$\begin{array}{l}\text { Modo de Ser } \\
\text { Humano } \\
\text { Co-existencialidad }\end{array}$} & \multirow[t]{7}{*}{$\begin{array}{l}\text { Vacío de } \\
\text { sentido }\end{array}$} & \multirow[t]{7}{*}{$\begin{array}{l}\text { Cumpli- } \\
\text { miento del } \\
\text { sentido } \\
\text { Vida plena }\end{array}$} \\
\hline & & Autodeterminación & & & \\
\hline & & Auto-trascendencia & & & \\
\hline & & Creatividad & & & \\
\hline & & $\begin{array}{l}\text { Afectividad senti- } \\
\text { mental }\end{array}$ & & & \\
\hline & & Contemplación & & & \\
\hline & & Esperanza & & & \\
\hline \multirow{6}{*}{$\begin{array}{l}\text { VOLUNTAD } \\
\text { DE PODER }\end{array}$} & \multirow[t]{6}{*}{ Psíquicos } & Hacer-productividad & \multirow[t]{6}{*}{ Autorrealización } & \multirow{6}{*}{$\begin{array}{l}\text { Fracaso } \\
\text { Frustra- } \\
\text { ción }\end{array}$} & \multirow[t]{6}{*}{ Éxito } \\
\hline & & Tenencia & & & \\
\hline & & $\begin{array}{l}\text { Pertenencia-relación } \\
\text { humana }\end{array}$ & & & \\
\hline & & Saber & & & \\
\hline & & $\begin{array}{l}\text { Afectividad } \\
\text { emocional }\end{array}$ & & & \\
\hline & & Recreación & & & \\
\hline \multirow{5}{*}{$\begin{array}{l}\text { VOLUNTAD } \\
\text { DE PLACER }\end{array}$} & \multirow[t]{5}{*}{ Sensibles } & Seguridad-abrigo & \multirow[t]{5}{*}{ Sobrevivencia } & \multirow[t]{5}{*}{ Muerte } & \multirow{5}{*}{$\begin{array}{l}\text { Satisfac- } \\
\text { ción } \\
\text { Vida } \\
\text { placentera }\end{array}$} \\
\hline & & Salud-nutrición & & & \\
\hline & & Descanso & & & \\
\hline & & Afectividad sensible & & & \\
\hline & & Contacto social & & & \\
\hline
\end{tabular}


sus actos pero constituyen también una prueba por cuya superación el espíritu crece. Sin embargo, el espíritu no existe sin más, independiente de sus contenidos. El espíritu no puede llevar a capricho su vida sin que ello influya en su ser mismo. La vida del espíritu - y esto caracteriza su esencia - no recibe su garantía del ser, sino también y definitivamente de lo válido. De la verdad, del bien. Si se aparta de aquí, él mismo se hace problemático en tanto que espíritu [...]. Si el espíritu apostasía de la verdad, enferma (Guardini 2000, 105-6).

\section{Líneas de orientación al sentido y sus niveles}

En la tarea de existir el hombre atraviesa por diversas y complejas situaciones vitales (Lepp 1963). Sin embargo, en todas ellas, el ser humano puede encontrar sentido al vislumbrar el significado que cada una tiene para continuar su propia existencia. Porque el sentido siempre corresponde a avanzar. Avanzar es conocer el contenido significativo de cada situación y, en efecto, actuar en consecuencia. Se abren ante la persona numerosas posibilidades de sentido de vida, o líneas de orientación al sentido que pueden ser agrupadas según tres niveles de valor que corresponden a los valores de creación, experiencia y actitud presentados por Frankl. Los valores de creación son todo aquello que damos de nosotros al mundo por la acción personal a través de proyectos y realizaciones humanos. Los valores de experiencia son todo aquello que recibimos del mundo como vivencias de valores y principios heredados y hechos propios: "es sentir por algo, por ejemplo, la obra de la naturaleza o la cultura; y también sentir por alguien, por ejemplo, el amor" (Frankl 2003a, 156 y 157). Y los valores de actitud se descubren a través del sufrimiento en las situaciones límite ante una realidad que no podemos cambiar. Cabe anotar aquí que el sufrimiento debe ser real e ineludible; si puede evitarse ha de evitarse, de lo contrario sería un sufrir inútil o masoquismo.

Dentro de los niveles de valores anteriormente presentados, se procede a establecer una agrupación de líneas de orientación al sentido que les corresponden por su carácter de don o receptividad del mundo, así como por su relación con el sufrimiento y las creencias religiosas. De 
otra parte hacen su aparición como opuestas a estos valores las líneas de orientación al contra-sentido.

Los valores de actitud se relacionan directamente con la verdad como valor principal (Cuadro 2). Es la verdad la que el hombre sale a encontrar y esto lo hace porque es libre. El sentido existencial por excelencia consiste para el hombre en su encuentro o no con la verdad: "la verdad que se yergue ante la propia vida la impulsa; de esa verdad el hombre saca precisamente el impulso para su práctica. De la verdad depende enteramente el valor de lo práctico. Sin verdad no hay libertad" (Polo 1993, 249).

En el segundo nivel se encuentran los valores de creación o creativos que se relacionan directamente con la bondad, como expresión del bien en la acción humana, es decir la bondad en su sentido moral, como acciones de carácter benéfico o beneficios en tanto corresponden a la naturaleza y la dignidad humanas del que las realiza y el que las recibe.

La acción humana no es meramente material, porque es libre, atravesada de sentido humano, y es expresión de nuestro amor, esto es, de nuestra aceptación o rechazo, de nuestra donación o retraimiento. Es, pues, el enlace, la mediación, entre lo temporal y lo intemporal [...]. La acción es el hacer capaz de humanizar el mundo (pero también de deshumanizarlo, incluso de destruirlo) (Sellés 2007, 384).

Y, en el tercer nivel, se encuentran los valores de experiencia o vivencia que se relacionan principalmente con la belleza, como aquello sublime que convoca al hombre a la admiración y la contemplación del cosmos, de sí mismo, de los otros y del Creador. Tienen que ver estos valores con las experiencias estéticas de la armonía y el orden, la simetría y la medida, el ritmo, la claridad y la proporción, integridad y perfección, descubiertos en el vivir cotidiano. La belleza referida al hombre mismo, se traduce en la capacidad de congregar hacia un mundo más humano, de ir a la reunión de la propia intimidad con la de los otros (Sellés 2007, 327).

Así visto, las líneas de orientación al sentido conducen a su descubrimiento en contraposición existencial de aquellas vías a través de las cuales la persona se dirige a la pérdida de sentido (Cuadro 2). 
Cuadro 2. Valores-líneas de orientación al sentido-líneas de orientación al contra-sentido

\begin{tabular}{|c|c|c|c|}
\hline $\begin{array}{l}\text { TIPOS DE } \\
\text { VALORES }\end{array}$ & $\begin{array}{l}\text { VALOR } \\
\text { PRIN- } \\
\text { CIPAL }\end{array}$ & $\begin{array}{l}\text { Líneas de orientación al } \\
\text { sentido (LOS) }\end{array}$ & $\begin{array}{l}\text { LIINEAS DE ORIENTA- } \\
\text { CIÓN AL CONTRASEN- } \\
\text { TIDO (LOCS) }\end{array}$ \\
\hline \multirow{5}{*}{$\begin{array}{l}\text { VALORES DE } \\
\text { ACTITUD }\end{array}$} & \multirow[t]{5}{*}{ VERDAD } & Sentido de convicciones & Confusión \\
\hline & & $\begin{array}{l}\text { Sentido de confianza y } \\
\text { compromiso }\end{array}$ & Desconfianza \\
\hline & & Sentido de religión-creencias & Descreimiento-Escepticismo \\
\hline & & $\begin{array}{l}\text { Sentido del sufrimiento } \\
\text { (dolor, culpa, muerte) }\end{array}$ & Angustia y evasión \\
\hline & & Sentido del humor & Conflicto y dramatización \\
\hline \multirow[t]{9}{*}{$\begin{array}{l}\text { VALORES } \\
\text { CREATIVOS }\end{array}$} & \multirow[t]{9}{*}{ BONDAD } & $\begin{array}{l}\text { Sentido del amor y la } \\
\text { amistad }\end{array}$ & $\begin{array}{l}\text { Odio, violencia e insensi- } \\
\text { bilidad }\end{array}$ \\
\hline & & Sentido de la familia & Individualismo \\
\hline & & Sentido del trabajo & $\begin{array}{l}\text { Utilitarismo o inutilidad } \\
\text { (pereza) }\end{array}$ \\
\hline & & Sentido del estudio & $\begin{array}{l}\text { Mediocridad, abulia o } \\
\text { ignorancia y curiosidad } \\
\text { desordenada }\end{array}$ \\
\hline & & $\begin{array}{l}\text { Sentido de participa- } \\
\text { ción ciudadana y política } \\
\text { (dinamismo social y valores } \\
\text { cívicos) }\end{array}$ & $\begin{array}{l}\text { Indiferencia, retaliación, } \\
\text { subversión }\end{array}$ \\
\hline & & $\begin{array}{l}\text { Sentido de servicio y solida- } \\
\text { ridad (voluntariado) }\end{array}$ & Egoísmo e irresponsabilidad \\
\hline & & $\begin{array}{l}\text { Sentido de la cultura y el } \\
\text { arte }\end{array}$ & Contracultura-subcultura \\
\hline & & Sentido del deporte & Apatía, indisciplina \\
\hline & & $\begin{array}{l}\text { Sentido de proyecto (metas, } \\
\text { ideales) }\end{array}$ & Inmediatismo \\
\hline \multirow[t]{3}{*}{$\begin{array}{l}\text { VALORES DE } \\
\text { VIVENCIA }\end{array}$} & \multirow[t]{3}{*}{ BELLEZA } & $\begin{array}{l}\text { Sentido del descanso } \\
\text { (contemplación, hobbies, } \\
\text { otros intereses) }\end{array}$ & Consumismo, aburrimiento \\
\hline & & $\begin{array}{l}\text { Sentido ecológico (natura- } \\
\text { leza y humanidad) }\end{array}$ & $\begin{array}{l}\text { Abuso y sobre-explotación } \\
\text { de los recursos }\end{array}$ \\
\hline & & Sentido de los sueños & Trivialidad y desencanto \\
\hline
\end{tabular}




\section{Categorías del modelo antropológico existencial del sentido}

El modelo de sentido se representa para su mejor comprensión sobre un plano cartesiano. A partir del punto de cruce de sus ejes que representan los radicales antropológicos del sentido, en el eje vertical y las líneas de orientación al sentido en el eje horizontal, se configuran cuatro categorías de sentido: objetivo, subjetivo existencial, subjetivo antropológico y contrasentido, a modo de cuadrantes que surgen entre las coordenadas. De la intensidad del despliegue o inhibición de los radicales y de la dirección positiva o negativa de las líneas de orientación surge la tipología de sentido en los cuadrantes.

Dicho de otro modo, las categorías generales de sentido corresponden a los cuatro cuadrantes del plano y son: sentido objetivo positivo, con radicales desplegados y valores positivos en las líneas de orientación al sentido, en el cuadrante superior derecho; sentido subjetivo existencial, con radicales desplegados y valores negativos en las líneas de orientación al sentido, en el cuadrante superior izquierdo; sentido subjetivo antropológico, con radicales inhibidos y valores positivos de líneas de orientación al sentido, en el cuadrante inferior derecho; y por último el contrasentido, con radicales inhibidos y valores negativos de líneas de orientación al sentido, en el cuadrante inferior izquierdo (Esquema 1).

Vale la pena destacar la diferencia entre la categoría de sentido subjetivo existencial y la categoría de sentido subjetivo antropológico. Consiste en que en la primera se da el repliegue de la persona a nivel existencial por la orientación equivocada o inventada de sus líneas vitales que, encausándose en oposición al sentido, se dirigen al contrasentido; mientras que en la segunda se da la inhibición de los radicales antropológicos del sentido, opacando la estructura personal desde la cual se realiza la apertura originaria a la existencia. En una y otra ya se barrunta la tragedia humana de vacío de sentido por la escisión entre el núcleo personal y su manifestación existencial; en la primera porque, aunque el núcleo personal conserva en parte su transparencia, los modos de manifestación vital no dan cuenta de ella pues son autodestructivos. En la segunda, porque el núcleo personal entra en opacidad interior y queda 
al margen, en un volcarse hacia afuera de actividad en diversos modos de hacer y tener cada vez más ajenos al carácter personal.

Esquema 1. Cuadrantes y tipos de sentido

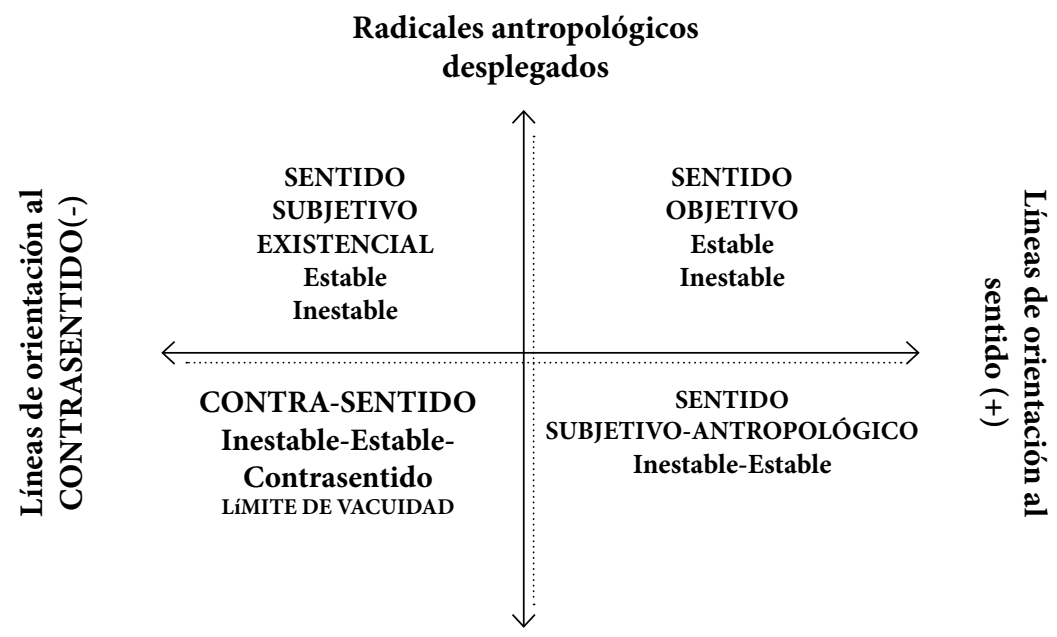

Radicales antropológicos
del sentido inhibidos

Quienes se encuentran en la disposición de apertura y de búsqueda de sentido, como también con la certeza del encuentro con la verdad que es actitud esperanzada y sostenida a lo largo de las circunstancias vitales, amables o difíciles, se sitúan en un campo de sentido objetivo. Se propone encontrar en cada situación la verdad que le es propia y con ello iluminar su propia verdad, su intimidad, para hacerle frente a su existencia con todo el entramado de complejidad que le caracteriza (Frankl 1992). El grado de persistencia con el que una persona se mantiene en esta tensión de no derrota frente a lo valioso de su existir y de su ser persona en el mundo, es la estabilidad en el sentido objetivo en el que ella se sitúa.

Sin embargo, tanto la intimidad humana como la existencia, son realidades complejas (Sellés 2003), en donde el discernimiento sobre la verdad presente en cada una, es decir el sentido, así como la presencia 
del valor, de la respuesta por el quién soy y quién estoy llamado a ser, y de lo que significa la propia vida y las cosas que en ella suceden, no siempre es diáfana. El sentido personal puede empañarse, hasta perderse. Sin embargo, siempre es posible recuperarlo porque la verdad personal está allí presente, aunque, a veces, aún oculta como experiencia propia.

Es por esto que la propia interioridad puede ocultarse para sí como un perderse a sí mismo y no encontrarse; es como un no ser, y aún así tener que seguir existiendo. $\mathrm{O}$ en algunas circunstancias, pretender haber descubierto un sentido, por el cual se gasta la vida, para después encontrarse con el hecho de que su valor era exiguo y pobre. O enraizarse en un sentido inventado, subjetivo e irreal, como un engaño propuesto a sí mismo para compensar el vacío de sentido objetivo y verdadero. Es el caso de quienes se ubican en las categorías de sentido subjetivo existencial y antropológico (Frankl 1978, 84).

En todos las categorías, el sufrimiento es el compañero inseparable de la existencia personal que aparece como un hecho inevitable en forma de pérdida, enfermedad, muerte, culpa, o tragedia capaz de oscurecer la existencia, hacerla irremediablemente amarga, si es vivenciado como una carga que bloquea y paraliza o como el dolor que hay que acallar. Es cuando se hace imperativo comprender que del sufrimiento también se deriva un sentido (Frankl 1984, 42). De lo contrario, en aquellos casos, las vías que se toman corresponden a contrasentidos, que además de ser ámbitos que no propician el encuentro con la verdad, en vez de constituirse en fuentes de sentido, pueden operar también como inhibidores de las disposiciones constitutivas del hombre para descubrirlo.

Las situaciones existenciales anteriormente mencionadas - de perderse a sí mismo, equivocarse en la percepción del sentido o asumir un sentido inventado producto de la propia imaginación o quererdesubican a la persona humana y la ponen en contravía de sí misma, de su realización existencial entendida en un modo humano de existir; al mismo tiempo la alejan de evidenciar su existencia como posibilidad de vida plena (Llano 2002).

La vida lograda es el deleite de lo vivido como vivido. La plenitud de una vida es el regalo que ofrece la existencia ante cada situación que ha sido vivida, enfrentada y respondida en profundidad de humanidad, es 
decir, en consonancia con la verdad del ser personal que se es, a pesar de los pesares. De este modo, la convicción de obrar bien, en actitud de transparencia frente a la verdad y de tensión positiva frente al hallazgo de la respuesta adecuada para cada pregunta existencial, constituye la aventura de vivir una vida buena cuya plenitud consiste en actualizar cotidianamente la unidad personal - que es cada uno- para evitar la desintegración interior, a causa de los hechos que enmarcan la ubicación existencial de cada quien y que a modo de vivencias se adentran en la subjetividad y la impactan de modo más o menos fuerte.

En efecto, el impacto de las experiencias vitales produce resonancias interiores en diversos niveles de la estructura natural y personal, que pueden llegar a empañar el sentido, de no estar la persona situada en la esperanza, al admitir la desgracia como derrota vital o por consentir en la intimidad la cerrazón en negación de la apertura que se es, desde y para el sentido. Cerrazón que ocurre tanto para sí mismo, como para con el mundo, replegándose así el centro personal en otro caso capaz de volcar su sentido a la personalidad y al mundo exterior de forma singular.

Este replegarse sobre sí mismo es un opacamiento de la luz interior, que ya no permite ver al interior para conocerse y poseerse, ni tampoco contemplar el afuera con admiración, en un abrirse a la vida con la confianza de ser y seguir siendo, es decir con horizonte de futuro. La esperanza en esta situación es relegada como utopía, como un imposible irreal que se deja de lado. Este es el estado de la persona humana que se sitúa en la categoría del contrasentido (Frankl 1994c).

En definitiva, se ha hecho referencia al ubicarse de la persona humana en diversas alternativas de sentido: el objetivo, el subjetivo en sus dos vertientes y el contrasentido (Esquema 1).

\section{Criterios para la definición de los tipos de sentido}

Con el fin de definir los tipos de sentido de vida se establecen unos criterios sobre los cuales evidenciar el mayor o menor despliegue de los factores de sentido. La variación en la intensidad de las manifestaciones de estos factores del sentido en la persona y su existencia, los radicales antropológicos y las líneas de orientación al sentido. Según la combina- 
ción de esos criterios se definen nueve tipos de sentido. Sobre la combinación de estos criterios se diseñaron dos instrumentos, un cuestionario y una entrevista focal, no incluidos en este artículo, para definir los grados de incidencia del despliegue de los radicales personales y de los ámbitos existenciales en el sentido de las personas (Cadavid y Díaz 2009). Se presenta a continuación la descripción general de cada uno de los criterios.

1. Despliegue-orientación: este criterio mide dos componentes: el despliegue antropológico y la orientación existencial. El despliegue se refiere al número y grado de desarrollo de los radicales antropológicos de sentido en la persona que, al ser constitutivos de ella, siempre están en posibilidad de desplegarse o de inhibirse. La orientación, por su lado, se refiere al número de líneas de orientación, ámbitos o caminos existenciales, en los que la persona despliega esos radicales personales en orientación positiva o negativa.

2. Actitud ante el valor: este criterio define el posicionamiento vital personal, la actitud moral fundamental (Hildebrand 2003) frente a sí mismo, es la valoración que la persona realiza de sus radicales antropológicos y de los diversos ámbitos de su existencia personal. Se considera una triple vertiente de este criterio: actitud objetiva cuando se sale al encuentro de sus valores antropológicos y existenciales; actitud subjetiva si se inventan tales valores o se rehúyen, se cierra la posibilidad de su encuentro; actitud límite si se muestra la incapacidad para percibir estos valores tanto los antropológicos como existenciales en un momento vital dado.

De la conjugación de estos dos criterios resultan las cuatro categorías generales de sentido:

- Despliegue radical positivo-orientación existencial positiva: sentido objetivo positivo.

- Despliegue radical positivo-orientación existencial negativa: sentido subjetivo existencial.

- Inhibición radical-orientación existencial positiva: sentido subjetivo antropológico. 
- Inhibición radical-Orientación existencial negativa: contrasentido.

3. Grado de interés vital: este criterio jerarquiza, según se mantenga más o menos, el grado de tensión de la energía vital (Lukas 1994, 264), entre la actitud interior de la persona y la respuesta a la realidad de su entorno existencial que presenta multiplicidad de preguntas existenciales que exigen respuestas. La jerarquía de las respuestas se determina como: muy alto, alto, medio, débil o nula.

4. Estabilidad vital: este criterio pondera la generalización de la respuesta vital personal en los distintos ámbitos existenciales (Imbernón y Campelo 2009). Puede ser estable si la respuesta vital se ubica en niveles muy alto o alto y esta se presenta en tres o más ámbitos existenciales; será inestable si esa presencia se da en dos o menos ámbitos existenciales, o en todo caso si el nivel de las respuestas vitales es de grado medio o débil en tres o más ámbitos existenciales.

La conjugación de estos últimos criterios determina los tipos de sentido estables o inestables. Los cuatro criterios combinados configuran los nueve tipos de sentido distribuidos en sus cuadrantes respectivos.

\section{Descripción de los tipos de sentido de vida}

Dentro de las cuatro categorías generales de sentido se establecen finalmente nueve tipos de sentido de vida. En la categoría de sentido objetivo positivo caben dos formas: estable e inestable; en la categoría de sentido subjetivo existencial caben también la forma estable e inestable; lo mismo sucede con la categoría de sentido subjetivo antropológico; y por último en la categoría de contrasentido además de estas dos formas se reconoce la forma de contrasentido límite de vacuidad o desesperación (Esquema 2).

A continuación se exponen los nueves tipos de sentido de vida propuestos desde el Modelo Antropológico-existencial del sentido según los criterios establecidos para su definición. Así mismo se presentan los rasgos característicos en que se manifiestan. 


\section{Sentido objetivo estable-positivo}

La actitud frente al valor es objetiva, porque la persona se reconoce positivamente en sus radicales personales y sale de sí mismo en conexión con la realidad, desarrollando una rica red de ámbitos existenciales positivos; $y$ abierta al encuentro del valor como expresión de significado, o contenido de cada situación, persona o circunstancia. El grado de la respuesta vital que ofrece a su existencia es muy alto porque mantiene un interés o tensión sostenida, entre su actitud interior o sí mismo y la realidad de sus circunstancias o existencia, como exigencia de dar respuesta a las preguntas que la realidad le presenta. Estable, porque esa calidad de su respuesta personal se despliega con gran fuerza y permanencia en la mayoría de los ámbitos vitales.

\section{Sentido objetivo inestable}

Positivo, porque contempla despliegue positivo de los radicales y ámbitos existenciales en los que se despliega. Es objetivo, porque la persona se reconoce en sus radicales y sale de sí mismo, en conexión con la realidad en sus ámbitos existenciales, y encuentra el valor de significado o contenido, de cada situación, persona o circunstancia. La respuesta vital que ofrece a su existencia es débil, no mantiene un interés o tensión sostenida entre su actitud interior o sí mismo y la realidad de sus circunstancias o existencia, que son la exigencia de respuesta a las preguntas que la realidad le plantea. Inestable, porque esa calidad de respuesta personal se despliega en algunos ámbitos existenciales con cierta fuerza.

\section{Sentido subjetivo-existencial estable}

Se muestra ambiguo porque comporta despliegue positivo de los radicales personales y líneas de orientación negativas configurándose una ambigüedad existencial, es decir, en el modo como despliega su sí mismo en unos ámbitos negativos para su desarrollo. En este caso quiere decir que la persona reconoce en sí misma algunos valores, significados y contenidos de sus radicales personales pero desarrolla un ejercicio vital subjetivo ya que no responde según ellos a la realidad y por lo tanto se desarrolla en ámbitos que lo orientan al contrasentido. La actitud 
ante el valor es Subjetiva porque la persona se repliega en sí mismo o se encierra, en una situación inventada o auto-construida de la realidad, y sin encontrar, o encontrando de modo precario, el valor, significado o contenido de cada situación, persona o circunstancia. La respuesta vital que ofrece a su existencia es alta, ya que mantiene un interés sostenido, una tensión entre su actitud interior y su realidad subjetivizada o inventada como respuesta a sus circunstancias existenciales. Estable porque se despliega en varios ámbitos vitales.

\section{Sentido subjetivo-existencial inestable}

Presenta despliegue positivo de los radicales personales y orientación negativa en los ámbitos existenciales, configurándose una ambigüedad existencial, es decir, la persona se centra en sí misma y reconoce el valor, significado o contenido en sus radicales personales, pero desarrollando un ejercicio vital en ámbitos existenciales que conducen al contrasentido. La actitud ante el valor es subjetiva porque la persona se repliega en sí mismo o encierra, en una situación inventada o auto-construida de la realidad, y sin encontrar o encontrando de modo precario el valor, significado o contenido de cada situación, persona o circunstancia. Cuenta con cierto despliegue de algunos de sus radicales personales, pero se despliega en algunos ámbitos existenciales negativos. El grado de interés vital que ofrece a su existencia es medio o débil, por lo tanto mantiene un cierto interés o tensión sostenida, entre su actitud interior y su realidad existencial orientada en forma de forma negativa, es decir subjetivizada o inventada. Inestable, porque se despliega en algunos ámbitos existenciales negativos.

\section{Sentido subjetivo-antropológico estable}

Contempla radicales personales inhibidos y orientación positiva de ámbitos existenciales; en este caso quiere decir que la persona está centrada en su existencialidad reconociendo el valor positivo de significado o contenido en sus ámbitos existenciales, pero situándose a espaldas del despliegue de sus radicales personales, que en este caso se presentan inhibidos. La actitud ante el valor es subjetiva porque la persona sale de sí hacia sus circunstancias, pero realiza su existencia 
sin encontrar o encontrando de modo precario el valor de lo humano de sí mismo en su modo de resolver su relación frente a cada situación, persona o circunstancia. Debido a que no introspecta esos valores como propios, y por lo tanto no los proyecta, los evita o los relega o no se confronta en ellos consigo mismo sino que busca fuera de sí sin encontrarse. La respuesta vital que ofrece a su existencia es alta, por lo tanto mantiene un interés o tensión sostenida, entre sí misma y su realidad existencial, pero sin involucrarse personalmente en ella. Estable porque se despliega en una red amplia de líneas de orientación al sentido.

\section{Sentido subjetivo-antropológico inestable}

Presenta radicales personales inhibidos y ámbitos positivos existenciales, la persona tiene una postura ambigua pues está centrada en su existencialidad reconociendo el valor positivo, significado o contenido en sus ámbitos existenciales, pero se sitúa de espaldas al despliegue de sus radicales personales. La actitud ante el valor es subjetiva porque sale de sí hacia sus circunstancias, pero realiza su existencia sin encontrar o encontrando de modo precario el valor de lo humano de sí mismo, en su modo de resolver su relación frente a cada situación, persona o circunstancia, ya que no introspecta esos valores como propios y por lo tanto no los proyecta, sino que los evita o los relega, o no se confronta en ellos consigo mismo. Busca fuera de sí sin encontrarse. La respuesta vital que ofrece a su existencia es media o débil, por lo tanto mantiene un cierto interés o tensión sostenida, entre sí mismo y su realidad existencial, pero sin involucrarse personalmente en ella. Inestable porque se despliega en algunos ámbitos existenciales positivos.

\section{Contrasentido estable}

Contrasentido porque tiene radicales personales inhibidos y líneas de orientación al contrasentido, es decir, negativas. Esto quiere decir que la persona se sitúa a espaldas del despliegue de sus radicales, en este caso inhibidos y se despliega en unos ámbitos negativos para su desarrollo configurando también un despliegue vital en sus ámbitos existenciales de contrasentido. La actitud ante el valor es subjetiva porque la persona tiene doble restricción, respecto a sí mismo y a sus circunstancias; no 
realiza su existencia encontrando el valor de lo humano de sí mismo, ni en su modo de resolver su relación frente a cada situación, persona o circunstancia, ya que no solamente no introspecta esos valores como propios y por lo tanto no los proyecta, sino que genera y proyecta antivalores frente a lo humano en ámbitos existenciales de contrasentido, es decir, configura un modo inhumano de ser. La respuesta vital que ofrece a su existencia es muy alta y alta, por lo tanto mantiene un interés o tensión sostenida, entre sí mismo y la realidad que se ha encargado de falsear en ámbitos negativos a modo de cinismo. Estable porque esa calidad de respuesta personal se despliega en numerosos ámbitos existenciales de contrasentido.

\section{Contrasentido inestable}

Contrasentido porque contempla radicales personales inhibidos y ámbitos existenciales orientados al contrasentido. La persona se sitúa a espaldas del despliegue de sus radicales y despliega su sí mismo en algunos ámbitos negativos para su desarrollo. La actitud ante el valor es subjetiva porque la persona tiene doble restricción, respecto a sí misma y a sus circunstancias. No realiza su existencia ni encontrando el valor de lo humano de sí mismo, ni en el modo de resolver su relación frente a cada situación, persona o circunstancia, es decir, no solamente no introspecta esos valores como propios y por lo tanto no los proyecta, sino que genera y proyecta antivalores frente a lo humano por situase en ámbitos de contrasentido, configura así un modo inhumano de ser. La respuesta vital que ofrece a su existencia es débil, mantiene un interés o tensión más o menos variable, entre sí mismo y su realidad existencial que se ha encargado de falsear. Inestable porque esa calidad de respuesta personal se despliega en no tantos ámbitos existenciales de contrasentido.

\section{Contrasentido límite de vacuidad}

Contrasentido porque denuncia radicales personales inhibidos y ámbitos existenciales de contrasentido. La persona se sitúa a espaldas del despliegue de sus radicales. No despliega su sí mismo, sino en ámbitos negativos para su desarrollo humano. La actitud ante el valor es Límite porque la persona tiene absoluta restricción de la percepción del valor 
de sí mismo y de su realidad existencial. Se encuentra en total desesperación y desesperanza lo que le puede llevar a la mayor beligerancia contra lo humano o al mayor abandono de él. La calidad de la respuesta vital que ofrece a su existencia es muy alta, en el caso beligerante; o baja o nula en el caso del abandono. Se encuentra atrapado en su realidad de absoluta oscuridad, sin salida posible. En el caso de la beligerancia se manifiesta contra sí mismo o contra otros, de modo determinante y definido; o en el caso del propio abandono se margina de sí mismo y puede atentar contra sí.

\section{Migración de los tipos de sentido}

Entre los tipos de sentido de los distintos cuadrantes caben múltiples posibilidades de migración, ya que la persona humana es dinámica, perfectible o defectible, y esto se manifiesta en el tipo de sentido de vida que sustenta su existencia. Estas variaciones se dan siempre dentro de cierta lógica existencial, como resultado de la dinámica propia del modo como la persona da respuesta a su existencia. Esta dinámica vital puede variar paulatinamente hacia el descubrimiento del sentido u optimización personal, o hacia el contrasentido, o despersonalización. En el primer caso, la persona se esfuerza por trabajar una red de contenidos y significados valiosos (Machado y Bandeira 2012); en el segundo, en cambio, la persona se descuida, se abandona del esfuerzo por el logro de valores vitales objetivos o asienta su existencia en contra de los mismos, auto-justificándose en valores subjetivos. Sin embargo esta variación, por paulatina que sea, cumple con unos recorridos entre los cuadrantes de sentido (Esquema 2).

En el caso de su optimización, la persona puede desplazar su sentido desde el cuadrante del contrasentido, primero saliendo de la estabilidad del contrasentido a la inestabilidad en el mismo y movilizándose a alguno de los cuadrantes de sentido subjetivo, antropológico o existencial; primero en el tipo estable y luego al inestable intentando aumentar en el factor de sentido positivo de cada cuadrante, en las líneas de orientación al sentido en el subjetivo antropológico o en los radicales personales en el subjetivo existencial. De esta manera, la persona se permea de 
Esquema 2. Flujo de migración entre cuadrantes y tipos de sentido

Radicales antropológicos del sentido (RAS+) DESPLEGADOS

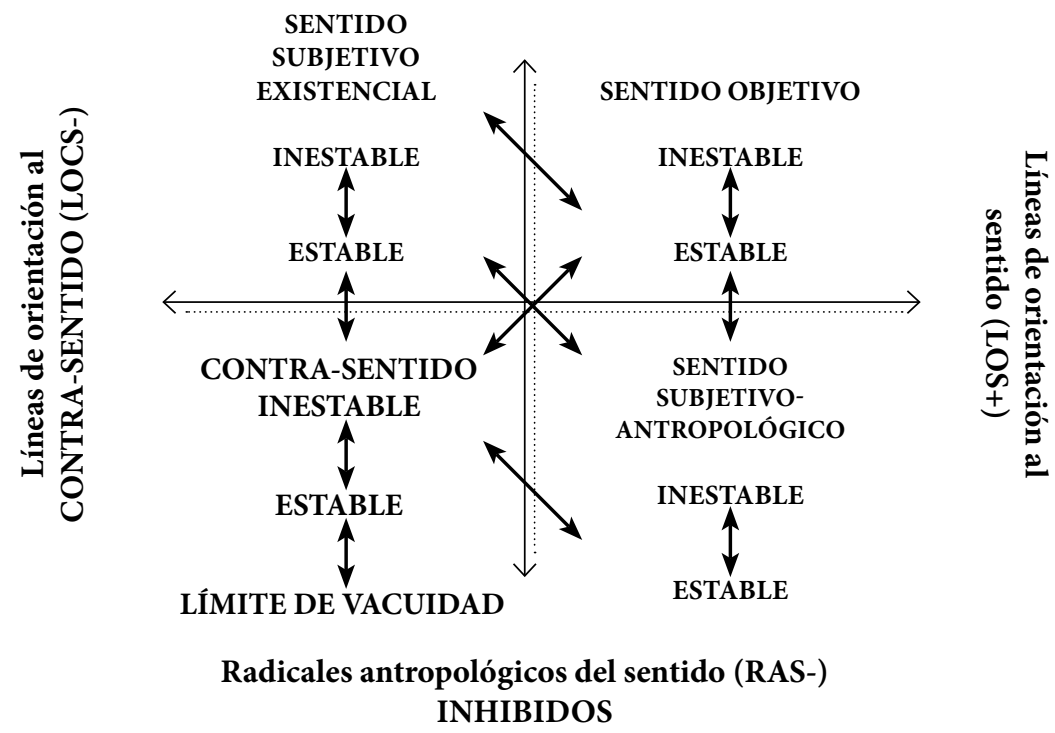

más sentido para hacer su ingreso al cuadrante del sentido objetivo, en su modo inestable $y$, finalmente, conquistar el sentido objetivo estable. Este último itinerario lo pueden cumplir las personas cuyos sentidos de vida se ubiquen en alguno de los cuadrantes subjetivos.

Por otra parte, la ruta hacia el contrasentido es también gradual, se puede realizar de modo inverso al itinerario anterior, y demuestra el abandono o contraposición de la persona en alguno de los factores positivos de sentido, que son constitutivos del cuadrante objetivo.

Otra manera de migrar en el sentido, es de forma abrupta, que se puede presentar como consecuencia de vivencias fuertes que producen un salto en la actitud de la persona frente a la realización del sentido en su existencia. Por ejemplo, del cuadrante objetivo al cuadrante del contrasentido, o viceversa. Menos abrupto, pero también importante, es el tránsito bidireccional entre los cuadrantes de sentidos subjetivo existencial y antropológico. Este cambio muestra una inestabilidad existencial por la inversión de los vectores correspondientes a los factores 
de sentido. No se considera posible dentro de esta lógica existencial que una persona sitúe su sentido al mismo tiempo en dos o más cuadrantes.

En resumen se han presentado los diversos factores, categorías, criterios y tipos de sentido que configuran el modelo antropológicoexistencial del sentido de vida, a modo de propuesta, para facilitar la comprensión del sentido de vida y así procurar su permanencia en la existencia de las personas.

\section{Conclusiones}

En conclusión, se expuso el modelo antropológico-existencial del sentido de vida a modo de propuesta conceptual susceptible de ser mejorada. El modelo está configurado por dos factores estructurales del sentido como son los radicales personales y las líneas de orientación existencial, que están representados en el plano del sentido a modo de ejes que, al cruzarse, dan origen en sus cuadrantes a las cuatro categorías generales de sentido. Además, se muestra cómo, con base en cuatro criterios establecidos, se configuran los nueve tipos de sentido propuestos y descritos.

El primer factor que constituye el modelo de sentido, es el de los radicales antropológicos del sentido, que son constitutivos de la persona humana como ser multidimensional, y que experimenta tensión en sentido positivo para su despliegue, o en sentido negativo para su inhibición, en cada uno de sus niveles. El despliegue de estos radicales permite que la persona se haga cargo en primer lugar de sobrevivir desde la dimensión biológica por sus radicales sensibles, que, en este modelo, corresponden con el dinamismo propio de la voluntad de placer. Su logro existencial constituye la satisfacción de las necesidades sensibles o una vida placentera y su inhibición conlleva a la muerte.

En segunda instancia se indica el despliegue de los radicales de la dimensión psíquica que conduce a la persona a su autorrealización. El logro de esta dimensión es entendido como éxito de la voluntad de poder y su inhibición es entendida como un fracaso vital.

En la dimensión espiritual la persona al desplegar los radicales de sentido se optimiza personalmente y resuelve su existencia como un modo de existir. El logro del despliegue espiritual de los radicales es el 
cumplimiento de sentido en una vida plena, entendida como la plenitud de ser quien se está llamado a ser. La inhibición de los radicales espirituales es la causa del vaciamiento de sentido personal.

El segundo factor de sentido, corresponde a las líneas de orientación existencial que se configuran en distintos niveles y se presentan como ámbitos vitales en los cuales la persona se manifiesta. Cuando son ricos de contenido humano valioso son facilitadores del desarrollo humano por su configuración constructiva y conducen al descubrimiento de sentido. En contraposición, las líneas existenciales que conducen al contrasentido cuando se trata de ámbitos vaciados de contenido humano y destructivos para el adecuado desarrollo de la persona, en definitiva deshumanizantes. Las líneas de orientación al sentido se presentan de acuerdo a tres niveles de valor que corresponden con los valores de creación, experiencia y actitud. Estos valores se refieren en primer lugar a la respuesta de la persona frente al mundo y su aporte personal en ofrecimiento de valores creativos; el aprendizaje o contemplación del mundo como ganancia de valores de experiencia; y la apertura o aceptación frente al sufrimiento en situaciones límite, ante el cual la persona se dispone con valores de actitud interior.

Sobre las categorías generales de sentido se concluye que únicamente aparece una de ellas como categoría de sentido objetivo, en la cual la persona asume una actitud objetiva ante sus radicales y ámbitos existenciales. Se presentan además dos categorías de sentido subjetivo; la categoría del sentido subjetivo existencial, cuando se presenta ambivalencia entre los radicales personales del sentido, que son conocidos en algún grado por la persona, y las líneas de orientación del sentido, en las que se encuentra existencialmente desorientada; o viceversa, la categoría del sentido subjetivo antropológico, cuando se presenta ambivalencia entre los radicales personales, de los que la persona se aleja o no se hace consciente, y las líneas de orientación de carácter positivo pero vaciadas de contenido de sí mismo. En la categoría del contrasentido la persona presenta desconexión de sí mismo y muestra unos radicales inhibidos, al mismo tiempo que muestra ruptura existencial contundente a través de cauces vitales de carácter negativo para su despliegue personal.

Por último, se enunciaron y describieron los criterios que se 
establecieron para definir los tipos de sentido. Con base en estos criterios, se hace posible notar el grado de despliegue o inhibición de los radicales personales en la persona, así como la intensidad de su orientación existencial en dos direcciones de sentido o contrasentido. Los criterios son: el grado de despliegue de los factores de sentido y su orientación positiva o negativa, la calidad de la actitud personal ante el valor como posicionamiento moral objetivo o subjetivo, el grado de interés vital como tensión y respuesta ante sí mismo y la propia existencia y es la estabilidad vital proporcional al menor o mayor número de ámbitos existenciales asumidos que denota estabilidad o inestabilidad del sentido.

A partir de la conjugación de los criterios mencionados se configuran nueve tipos de sentido a saber: el sentido objetivo estable e inestable, el sentido subjetivo existencial estable e inestable, el sentido subjetivo antropológico estable e inestable y contrasentido estable e inestable y el contrasentido límite de vacuidad.

El modelo de sentido incluye la posibilidad de migración entre los distintos tipos de sentido vital en referencia a la dinámica personal y existencial siempre susceptible de perfeccionamiento u opacamiento.

Se intenta con esta exposición contribuir al mejoramiento personal y social por la relevancia fundamental de la búsqueda y descubrimiento del sentido de vida personal, y con ello motivar a nuevas investigaciones que hagan cada vez más diáfana la aproximación al sentido de vida.

\section{Bibliografía}

Aquino, Tomás. 2001. Suma de Teología, I-II. Tratado de la bienaventuranza (qq. 1-6). Madrid: BAC.

Aranguren, Javier. 2003. Antropología filosófica. Una reflexión sobre el carácter excéntrico de lo humano. Madrid: McGraw-Hill.

Aranguren, Luis A. 2000. El reto de ser persona: una aproximación a la antropología de Jean Lacroix. Madrid: BAC.

Aristóteles. 2007. Ética Nicomaquea. Trad. y notas de Julio Pallí Bonet. Barcelona: RBA Libros (Biblioteca Clásica Gredos).

Burgos, Juan Manuel. 2003a. El personalismo. Autores y temas de una 
filosofía nueva. Madrid: Palabra.

Burgos, Juan Manuel. 2003b. Antropología: una guía para la existencia. Madrid: Palabra.

Cadavid, María Victoria y Víctor M. Díaz . 2009. “Tipos de sentido de vida en los jóvenes universitarios en Bogotá”. Tesis Maestría en Educación. Chía: Universidad de La Sabana.

Frankl, Viktor Emil. 1984. Psicoterapia y humanismo. ¿Tiene un sentido la vida? México: FCE.

Frankl, Viktor Emil. 2000. El hombre doliente. Fundamentos antropológicos de la psicoterapia, 3 edición. Barcelona: Herder.

Frankl, Viktor Emil. 2003a. El hombre en búsqueda de sentido. Barcelona: Herder.

Frankl, Viktor Emil. 2003b. La idea psicológica de hombre. Madrid: Rialp.

Frankl, Viktor Emil. 1994a. La voluntad de sentido. Escritos selectos sobre logoterapia. Barcelona: Herder.

Frankl, Viktor Emil. 1994b. Logoterapia y análisis existencial. Barcelona: Herder.

Frankl, Viktor Emil. 1994c. Ante el vacío existencial: hacia una humanización de la psicoterapia. Barcelona: Herder.

Frankl, Viktor Emil. 1978. Psicoanálisis y existencialismo. De la psicoterapia a la logoterapia. México: FCE.

Frankl, Viktor Emil. 2001. Psicoterapia y existencialismo. Escritos selectos sobre logoterapia. Barcelona: Herder.

Frankl, Viktor Emil. 1992. Teoría y terapia de las neurosis. Iniciación a la logoterapia y al análisis existencial. Barcelona: Herder.

Franquet, María J. 1996. Persona, acción y libertad. Las claves de la antropología en Karol Wojtyla. Pamplona: EUNSA.

Freire, José B. 2002. El Humanismo de la Logoterapia de Viktor Frankl. La aplicación del análisis existencial en la orientación personal. Pamplona: EUNSA.

García, Claudio. 2003. Cita a ciegas. Sobre la imprevisibilidad de la vida. Reflexiones a partir de la obra Sincronización en Binkerwald de Viktor E. Frankl. Buenos Aires: Ediciones San Pablo. 
García, Claudio. 2004. Viktor E. Frankl, La humanidad posible. México: Ediciones LAG.

Guardini, Romano. 2000. Mundo y persona. Madrid: Encuentro.

Hildebrand, Dietrich Von. 2001. El corazón. Un análisis de la afectividad humana y divina. Madrid: Palabra.

Hildebrand, Dietrich y Alice Von. 2003. Actitudes morales fundamentales. Madrid: Palabra.

Juan Pablo II. 1995. Queridísimos jóvenes. Barcelona: Plaza y Janés.

Lacroix, Jean. 1980. Filosofía de la culpabilidad. Barcelona: Herder.

Lepp, Ignace. 1963. Filosofía cristiana de la existencia. Buenos Aires: Ediciones Carlos Lohlé.

López Quintás, Alfonso. 1994. Cómo formarse en ética a través de la literatura. Madrid: Rialp.

Lukas, E. 1994. "Para validar la logoterapia”. En Frankl, V. E. (1994a). La voluntad de sentido. Escritos selectos sobre logoterapia. Barcelona: Herder.

Machado, Wagner de Lara y Bandeira, Denise R. 2012. "Bem-estar psicológico: definição, avaliação e principais correlatos”. Estudos de psicologia (Campinas. 29/4:587-95). Recuperado el 8 de noviembre de 2013 de: http://www.scielo.br/scielo.php?script=sci_arttext\&pi$\mathrm{d}=$ S0103-166X2012000400013\&lang=pt

Malo, Antonio. 2004. Antropología de la afectividad. Pamplona: Eunsa.

Marías, Julián. 1987. La felicidad humana. Madrid: Alianza Editorial.

Martínez, Emma. 2011. Buscadores de felicidad. Madrid: Narcea.

Polo, Leonardo. 1987. Curso de teoría del conocimiento, vol. I. Pamplona: Eunsa.

Polo, Leonardo. 1993. Quién es el Hombre. Un espíritu en el mundo. Madrid: Rialp.

Polo, Leonardo. 2005. "Lo radical y la libertad." Cuadernos de Anuario filosófico. No 179. Pamplona: Universidad de Navarra.

Polo, Leonardo. 2007. “Ética socrática y moral cristiana” Anuario Filosófico. 40 (3), 547-570. Pamplona: Universidad de Navarra. 
Quitmann, Helmut. 1989. Psicología humanística. Conceptos fundamentales y trasfondo filosófico. Barcelona: Herder.

Scheler, Max. 1998. Ordo amoris. Madrid: Caparrós.

Sellés, Juan Fernando. (pro-manuscripto) "Los afectos del espíritu. Una propuesta de ampliación del planteamiento clásico".

Sellés, Juan Fernando. 1997. Curso breve de teoría del conocimiento. Bogotá: Universidad de La Sabana.

Sellés, Juan Fernando. 1998. La Persona Humana. Parte III Núcleo personal y manifestaciones. Bogotá: Universidad de La Sabana.

Sellés, Juan Fernando. 2007. Antropología para inconformes. Madrid: Rialp.

Sellés, Juan Fernando. 2010. “Los filósofos ylos sentimientos”. Cuadernos de Anuario Filosófico. 227. Pamplona: Universidad de Navarra.

Tobías, Cristina, y García-Valdecasas, José. 2009. "Psicoterapias humanístico-existenciales: fundamentos filosóficos y metodológicos” Revista de la Asociación Española de Neuropsiquiatría 29/104:437-53. Recuperado el 8 de noviembre de 2013 de: http://scielo.isciii.es/scielo. php?script=sci_arttext\&pid=S0211-57352009000200010\&lang=pt

Wojtyla, Karol. 1982. Persona y acción. Madrid: BAC.

Yepes Stork, Ricardo y Javier Aranguren. 1996. Fundamentos de antropología: hacia un ideal de la excelencia humana. Pamplona: Eunsa.

Yepes Stork, Ricardo. 1997. "La persona y su intimidad." Cuadernos de Anuario Filosófico, 48. Pamplona: Universidad de Navarra. 